\title{
A viagem das idéias
}

\author{
RENan Freitas Pinto
}

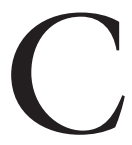

OM O PRESENTE título queremos sugerir que as idéias, ao percorrerem espaços próximos e distantes, conectando homens e épocas, possuem, em determinadas situações especiais, em certos momentos singulares, a capacidade de se imporem como o sistema de pensamento predominante, a partir do qual se passa a sentir, a agir e a perceber o mundo das coisas e dos homens. Há também as situações em que as idéias perdem seu impulso original em momentos desfavoráveis à sua propagação, extraviam-se e são eclipsadas.

Nessa perspectiva, queremos sugerir que o processo de formação do pensamento que construiu a Amazônia como um espaço natural e cultural vem, ao longo dos últimos cinco séculos, produzindo e continuamente reinventando, a partir de um conjunto relativamente limitado de idéias, as percepções que se tornaram as mais persistentes, dentro certamente do quadro mais amplo e diversificado da geografia do Novo Mundo.

Um outro aspecto certamente digno da atenção de toda investigação em torno do desenvolvimento da história das idéias sobre a Amazônia é que esse processo tem envolvido uma gama bastante diferenciada de campos da ciência e do pensamento, mas tem se concentrado de forma especial em áreas como a da história natural, da geografia, da antropologia.

$\mathrm{O}$ aspecto, entretanto, de maior interesse é aquele revelado por esse tipo de prospecção em torno de quais as idéias matrizes que foram historicamente se configurando para constituir esse núcleo a partir do qual vem sendo geradas as noções diferenciais entre a civilização e a barbárie, ou seja, mapear, no trajeto do pensamento moderno, as origens das noções que separaram o mundo por meio de noções preconceituosas.

Um dos momentos heurísticos da história das idéias sobre o Novo Mundo certamente é a famosa disputa entre Sepúlveda e Las Casas em torno do direito que possuiriam ou não os europeus - em particular os espanhóis - de estabelecerem legitimamente a escravização das populações indígenas fundando-se sobretudo nos argumentos de Aristóteles, segundo os quais os povos derrotados em guerra estariam forçosamente reduzidos à condição de escravos. De modo semelhante estaria também sugerida a idéia de que existem povos que, em razão de sua inferioridade racial, estariam fadados a serem submetidos e levados à situação da escravidão.

Sobre esse debate, historiadores cujas obras estariam fortemente identificadas com o Novo Mundo como o italiano Antonello Gerbi (O Novo Mundo: história de uma polêmica 1750-1900) e o norte-americano Lewis Hanke (Aristóteles e os 
indios americanos), empenharam-se em demonstrar as amplas conseqüências e desdobramentos que produziram os argumentos dessa polêmica até o presente. Ou seja, durante todo esse longo e complexo processo de formação dos países e povos do Novo Mundo, a idéia da superioridade branca e européia sobre a fragilidade dos povos indígenas e dos negros e mestiços tem estado presente em diferentes gradações, realimentando constantemente não apenas nosso senso comum, mas envolvendo também as temáticas de pesquisadores e especialistas, em particular no que vem sendo identificado como o terreno da formação sociocultural da América indígena, negra e mestiça.

De outra parte, o arsenal de idéias e valores com os quais nos percebemos e nos representamos como brasileiros, mexicanos, bolivianos etc. tem suas matrizes em um conjunto restrito de representações, que vêm se cristalizando e se transformando ao longo de nossa história até o presente.

São essas idéias que, portanto, têm estado presentes na maior parte dos intentos para explicar e decifrar a condição cultural do Novo Mundo e da Amazônia e que terminaram por se constituírem em aspectos de evidente relevância para a construção da história do pensamento social ocidental moderno.

A Amazônia como um dos espaços mais característicos do Novo Mundo esteve, desde o início da construção da filosofia do mundo moderno, presente nas reflexões em torno de temas como o surgimento da sociedade e do Estado, do reconhecimento da desigualdade entre os homens e os povos, das novas geografias, e continua a fornecer alimento para a recriação de novas polarizações, como a recriação do bom selvagem em idéias com a de "povos da floresta" e de "ribeirinhos", portanto, de um novo romantismo social.

O desenvolvimento das matrizes do pensamento ocidental que se aproximam e se envolvem com o conjunto de idéias que constituem o pensamento social sobre a Amazônia, em alguns casos se referem a pensadores que não trataram diretamente da região, mas que se envolveram com questões que se relacionam profundamente com as idéias centrais que têm sido utilizadas para descrevêla, pensá-la, interpretá-la. E há aqueles que, ao tomarem mais diretamente a região como objeto de suas reflexões, terminaram por trazer alguma forma de contribuição para uma compreensão mais aceitável da história das idéias sociais no Brasil. Entretanto, esse é um terreno ainda muito pouco explorado.

Investigar a história das idéias que dão forma ao pensamento social sobre a Amazônia implica retomarmos obrigatoriamente a leitura de autores centrais do pensamento moderno, entre os quais têm sido freqüentemente estudados à luz de novas abordagens, Montaigne, Montesquieu, Hobbes, Rousseau e Hegel, da mesma forma que também fica implícita a idéia de que é necessário prosseguir buscando, nas diferentes manifestações do pensamento filosófico e social que acontecem após esses autores, o desenvolvimento de idéias matrizes por eles formuladas, ou o acontecimento de novos conceitos e noções sugeridos pela emergência de novos postulados e paradigmas. 
Nessa mesma ordem de questões é possível ainda lembrar que o surgimento de algumas das novas ciências e epistemes representativas do modo de pensar moderno tem, em algum grau, relações com a incorporação do Novo Mundo e da diversidade da geografia humana aos quadros de referência inaugurais desses novos campos do pensar. Apenas para exemplificar, hoje, quando se fala em Amazônia, estamos diante da produção de um novo senso comum sustentado pelas noções de meio ambiente, biodiversidade, sociodiversidade, desenvolvimento sustentável, populações ribeirinhas, povos da floresta, que são as expressões correntes e presentes em praticamente todos os escritos que têm sido produzidos sobre a região e que freqüentemente carregam consigo conteúdos de imobilismo social e conservadorismo romântico, quando se trata sobretudo de lidar com a situação e o destino das populações locais.

Antecede a esse momento atual a revolução geográfica representada pela inclusão de novos espaços aos movimentos de ocidentalização nos quais se estabelecem de forma cada vez mais freqüente as oposições entre civilizado e primitivo, civilização e barbárie, modernidade e tradição. É a partir também dessa geografia ampliada que se consolida na perspectiva do europeu um pensamento político de conteúdo cada vez mais eurocêntrico, cujos elementos principais se organizam em torno dos processos de formação do Estado nacional, da sociedade civil, da organização da cultura dos países americanos como prolongamentos da Europa.

Ao mesmo tempo, esse pensamento político construía a própria noção de Estado tendo como ponto de partida o cenário da vida selvagem e do estado de natureza, criada a partir da imagem do Estado nacional europeu, em contraste com as formas de organização política características dos povos do Oriente, das terras exóticas, dos reinos de tiranos. Com inúmeras gradações, o mundo fora da Europa abrigava desde as terras dos selvagens - dos bons selvagens - até aos domínios onde não se apresentavam sinais do que podia ser visto e identificado com sociedade civil.

Entre as leituras necessárias para a reconstrução de nosso quadro de referência certamente permanece Os canibais, o conhecido ensaio de Montaigne sobre a vida dos indígenas que os europeus encontraram na América.

Como já demonstrou de modo definitivo o estudo cuidadoso realizado por Afonso Arinos de Melo Franco, intitulado $O$ indio brasileiro e a Revolução Francesa: as origens brasileiras da teoria bondade natural, Montaigne inspirouse, não como afirma, no testemunho oral de um homem simples que havia vivido na América, mas, na verdade, nas obras já publicadas em seu tempo, em primeiro lugar a de Jean de Léry Viagem à terra do Brasil e as de André Thévet, As singularidades da França Antártica e a parte referente ao Brasil de sua Cosmografia universal, para retratar a vida dos selvagens do Brasil, com isso construindo a notoriedade de seu ensaio sobre Os canibais.

Montaigne, com os seus canibais, estava decisivamente ajudando a fundar uma das vertentes da antropologia assentada em um ponto de vista relativista e 
contribuía para acusar seus contemporâneos de eurocentrismo e etnocentrismo. Acreditava que o conhecimento cada vez maior de povos distantes deveria contribuir para melhorar os padrões da organização política das nações da Europa. Nesse sentido, como nos demais, parece que as idéias antropológicas de Montaigne foram idéias derrotadas e ficaram relativamente esquecidas até o presente.

Buffon é um pensador que teve suas idéias largamente aceitas sobre o Novo Mundo e desempenhou um papel destacado na construção da identidade européia e de concepções científicas que foram centrais na formação do pensamento científico moderno. A imagem que produz do Novo Mundo a partir de seus escritos é fortemente marcada pela noção de que existe um condicionamento geográfico e climático que limita a plena evolução do Novo Mundo aí incluídas vida animal, vegetal e humana.

O estágio de desenvolvimento em que se encontram as formas de vida existentes na América pertence a um momento inferior em que os seres são frágeis e débeis, quando comparados com os seus correspondentes do clima e do meio europeus. A natureza do Novo Mundo seria menos ativa em seus princípios de ação, o que implicaria o fato de que as formas de vida ali existentes apresentariam uma fragilidade e debilidades relativas.

Nesse mesmo sentido, a vida humana também corresponderia a esses estágios pouco desenvolvidos da natureza, sendo, portanto, a história humana parte da história natural em determinado estágio de sua evolução. Ao reconhecer a inferioridade das sociedades humanas existentes nas diferentes partes da Améri$\mathrm{ca}$, Buffon reconhece graus diferenciados de adaptação ao meio físico, buscando por meio desse recurso propor um sistema de evolução fundado em determinadas vantagens climáticas e de espaço.

Ao se referir a grupos de indígenas da Amazônia, Buffon é atraído, sobretudo, por sinais que identificam esses grupos como portadores de costumes selvagens. E de um ponto de vista evolutivo são classificados entre os povos mais primitivos. O parâmetro da civilização é o do homem branco europeu. E a cor da pele, quanto mais escura, mais se distancia desse padrão do civilizado. Sua atenção é particularmente despertada para alguns costumes tribais, entre eles certamente o da guerra, da antropofagia e da produção por parte desses povos de algumas deformidades corporais, como é o caso da descrição que faz dos índios Omágua segundo a qual mantinham a prática de achatar as cabeças das crianças.

Para Buffon, os índios do Brasil são, em sua grande maioria, primitivos e resistentes aos valores da civilização, a não ser os poucos grupos que passaram a manter relações de comércio com os portugueses. Na região do rio das Amazonas, em função do clima pouco sadio, as mulheres são menos fecundas e têm sua esterilidade aumentada quando são obrigadas a viver em regiões com situação climática mais desfavorável, aumentando assim a freqüência de abortos. Há, portanto, em suas referências ao vale amazônico, a idéia de que tal ambiente não favorece o desenvolvimento da civilização e que a humanidade que ali se encon- 
tra situa-se em estágio bastante anterior ao do desenvolvimento das sociedades civilizadas da Europa e de outras regiões do mundo.

Buffon, portanto, caracteriza a Amazônia como um experimento da natureza ainda em formação, mas apresentando condições desfavoráveis ao pleno desenvolvimento das formas de vida naturais e humanas. Essas idéias propagaram-se e foram, em alguma medida, adotadas por autores até o presente e contribuindo para cimentar as idéias mais correntes do senso comum sobre a região.

Concepções muito próximas, portanto, encontramos na forma pela qual Hegel, em seus famosos cursos de filosofia da história universal apresentava as regiões e povos do mundo, tendo como marco de identificação a noção de espírito da história. Em sua reflexão sobre a relação entre a geografia e a civilização, apresenta uma crítica de alcance significativo ao determinismo geográfico; entretanto, sua referência ao vale do Amazonas praticamente se limita, como também no que diz respeito a outras regiões do Mundo a reproduzir argumentos, explicações e exemplificações extremamente próximas às de Buffon.

Vamos encontrar também nas anotações sobre os povos indígenas do brasileiro Alexandre Rodrigues Ferreira - Viagem filosófica - exemplos e argumentos igualmente inspirados nas idéias de Buffon, ou seja, na caracterização negativa das terras e gentes da Amazônia, propondo o estudo dos povos indígenas como um ramo da história natural.

De modo breve, passamos a assinalar os elementos centrais do que poderíamos considerar a antropologia de Alexandre Rodrigues Ferreira e apontar, sob diversos prismas, o quanto sua interpretação do homem amazônico é um dos traços fundamentais do pensamento científico tal como se desenvolveu em relação aos povos e ao meio natural dessa parte da América. Sua obra é também exemplar no sentido de evidenciar as limitações que marcavam o trabalho da ciência em uma região como a Amazônia no século XVIII. Sua obra também evidencia o envolvimento do cientista com um padrão de política colonial limitado e decadente como era o de Portugal no momento em que o naturalista baiano empreende seu ambicioso trabalho de inventário científico do vale do Amazonas.

Ao procurarmos traçar o limite de nossa abordagem sobre a formação do pensamento social brasileiro na Amazônia, obviamente tivemos a dificuldade de escolher entre os vários pensadores e intérpretes que se dedicaram a compreender a região, sob o ponto de vista preferencial da formação do povo brasileiro nesta parte do país. Partindo de nossa própria experiência com leituras sistemáticas e outras bastante livres, nos decidimos por incluir um grupo bastante restrito de autores para, a partir deles, formular uma primeira sondagem na direção dos núcleos do pensamento social que ao longo desses séculos de encontro de civilizações têm emergido às vezes nas entrelinhas dos seus escritos, às vezes de modo categórico. Os autores e as obras que mencionamos aqui contribuíram de forma decisiva para construir a idéia de Amazônia que tem estado presente desde o início de sua história até hoje. Autores às vezes tão surpreendentes quanto os seus próprios temas. 


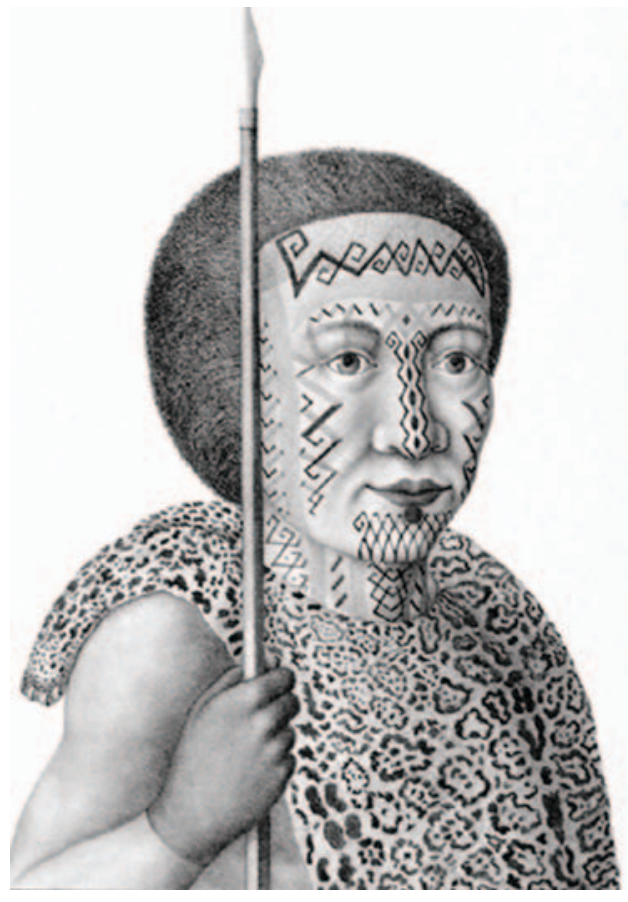

A leitura do Diário de Samuel Fritz apresenta-se bem como um desses exemplos. Ela nos oferece informações sobre um momento, sob vários aspectos, particular da ocupação da

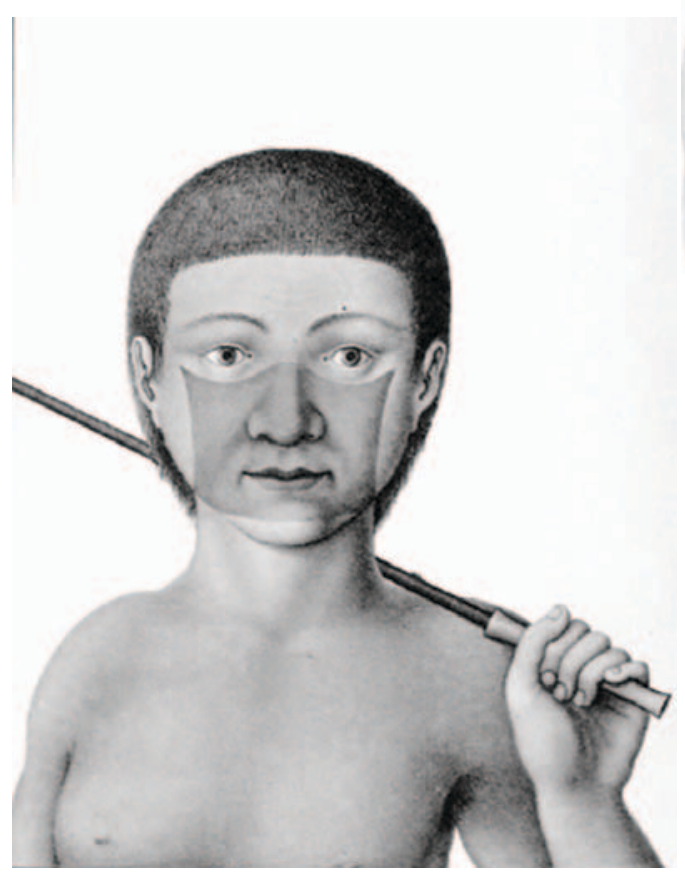

Nossa convicção principal em relação a essa literatura em seu conjunto é a de que é necessário o trabalho de recuperação da obra integral de seus autores para que, por meio de sua leitura, iluminada por novos paradigmas e enfoques teóricos, seja possível não apenas a reconstrução do pensamento social sobre a Amazônia, mas a revelação e descoberta de elementos mais significativos da formação sociocultural dessa parte do Brasil.

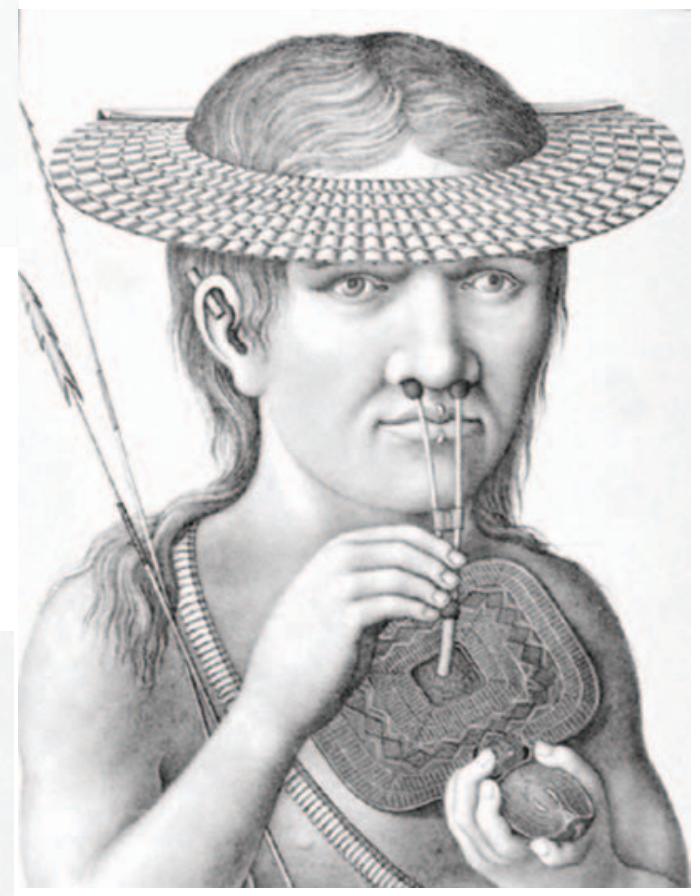

Amazônia por espanhóis e portugueses. O ponto de vista de suas anotações é o de um missionário ao serviço do reino da Espanha e da Companhia de Jesus em sua versão espanhola. Portanto, quando se refere a colonos e autoridades portugueses, utiliza termos quase sempre negativos, buscando caracterizar a presença lusitana no vale como uma ameaça ao trabalho da civilização e cristianização das populações nativas. 

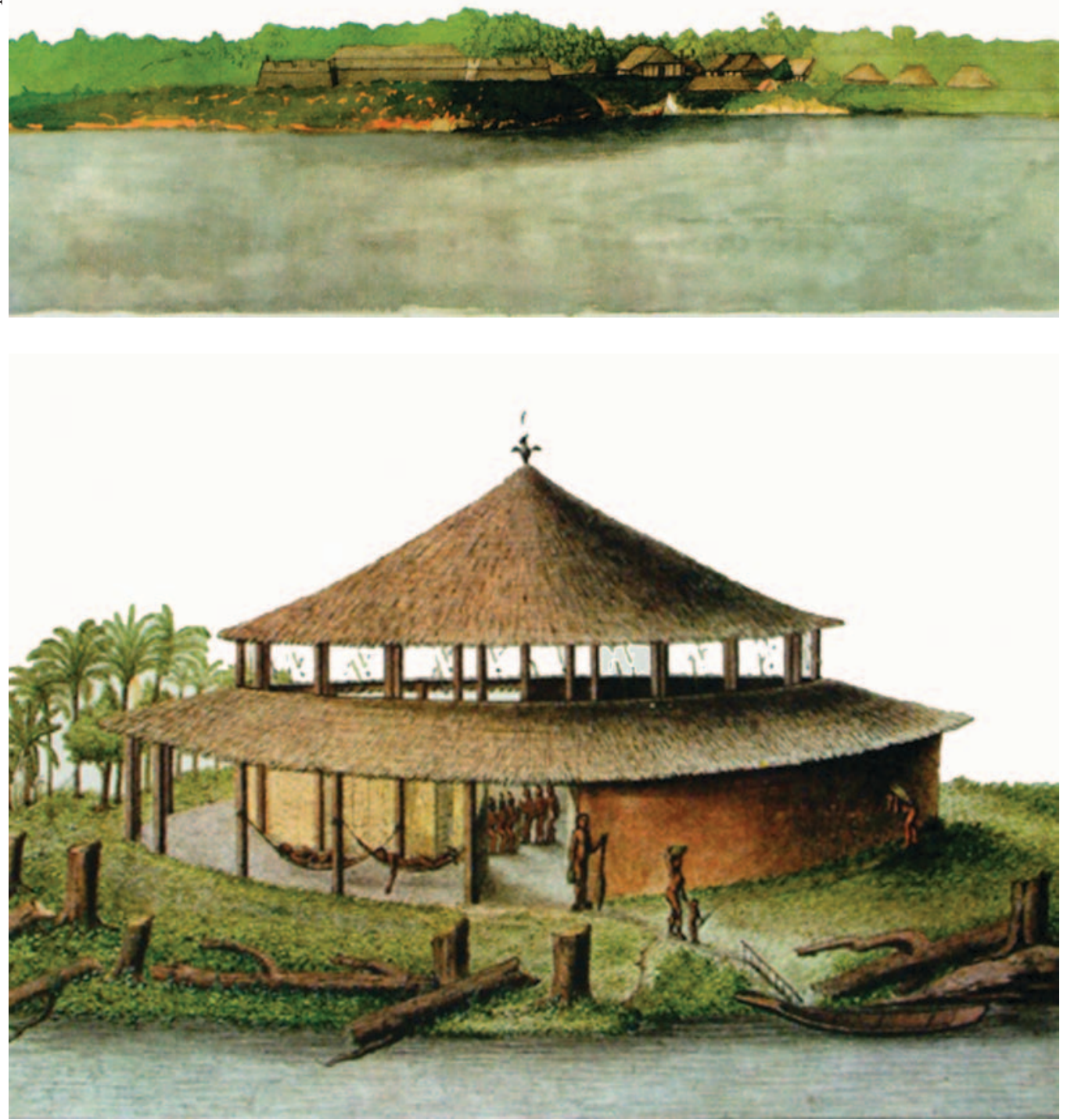

Povos indígenas (à esq.) e malocas em desenhos do brasileiro Alexandre Rodrigues Ferreira.

Para Samuel Fritz, o que diferencia fundamentalmente os portugueses dos espanhóis é que os primeiros são predadores dos povos indígenas por meio de guerras e escravização, enquanto os espanhóis, mesmo tendo usado métodos igualmente violentos em seus contatos com os povos indígenas, têm modificado o conteúdo dessas relações em direção a uma conduta de convivência marcada pela tolerância e pela cooperação mútua. 
As idéias do missionário Samuel Fritz tornaram-se bastante conhecidas ao longo da vasta extensão do vale amazônico, onde sua influência e obra de organização de bases missionárias conseguiu chegar, estando tal presença identificada com o nascimento de várias das cidades, vilas e lugares do espaço configurado como a Amazônia portuguesa.

A obra de Samuel Fritz não está, portanto, apenas contida nas breves anotações incompletas de seu Diário de viagem. Ele se prolonga até às duas ações, na medida em que se dedicou ao estudo de diferentes línguas indígenas, produziu duas versões de importante carta geográfica que serviu de ponto de partida para toda a cartografia subseqüente, aí incluída a carta desenhada por La Condamine que, sobre a carta de Fritz, escreveu um comentário que passou a fazer parte inseparável daquele documento. Sua obra constitui, portanto, momento inaugural do pensamento social sobre a Amazônia e, em particular, sobre o pensamento antropológico. Suas notas sobre os vários povos e grupos indígenas com os quais conviveu tanto do lado espanhol como do lado português foram de inegável importância para sua identificação e reconhecimento mesmo em tempos recentes. Apesar de seus posicionamentos contrários aos movimentos de mobilização e de resistência indígena ao processo de dominação e expansão colonial sobre seus territórios, Samuel Fritz faz o registro de alguns desses movimentos, um de seus líderes tendo sido algumas vezes mencionado pelo padre, o chefe Aiporeva, que apesar de seus aconselhamentos para que este deixasse de incitar e levantar os índios contra os europeus, manteve-se resistente à conciliação.

Um outro dado que não pode ser desprezado em relação ao Diário de viagem é a sua significação e valor como texto de literatura narrativa. Há, no que restou da versão original, alguns dos elementos que se tornarão freqüentes nos textos literários sobre o vale amazônico, entre os quais vale destacar a descrição de elementos típicos da paisagem, a ocorrência de fenômenos naturais de conseqüências às vezes trágicas para as populações nativas como as inundações, as tempestades e os terremotos. Não faltam também situações de perigo e de aventura, quando o próprio padre Samuel Fritz enfrenta índios hostis e animais ferozes. Há uma cena particularmente dramática em que um enorme jacaré tenta subir na canoa em que estava o padre, que só não é arrastado e devorado pelo animal graças à intervenção do garoto que o acompanhava. As descrições que faz dos indígenas, de suas línguas, costumes, crenças, artes e técnicas, constituem, além de elemento de significação literária, informações de inegável relevância etnológica, sobretudo quando se constata a raridade ou mesmo a inexistência de referências a determinados grupos e etnias freqüentemente mencionadas em passagens do Diário.

Em resumo, é possível afirmar que seu Diário deve ser considerado como uma das expressões da literatura de revelação do vale amazônico, já possuindo rigorosamente a maior parte dos elementos que vão construir a mais forte tradi- 
ção narrativa sobre essa parte do Novo Mundo. Aspecto que não deve, entretanto, ser dissociado da importância que possuem essas anotações para a identificação da Amazônia da perspectiva da ciência, em particular na fundação dos campos da geografia, da cartografia e da etnologia.

Não podemos, reportando-nos a esses primeiros autores, esconder o fato de que a leitura da obra do padre João Daniel - Tesouro descoberto no rio das Amazonas - foi a que mais nos impressionou em meio a todas as que realizamos. Em primeiro lugar porque escrita no cárcere em que o jesuíta foi mantido em Portugal, onde conseguiu, burlando as normas da prisão, produzir seu volumoso inventário do vale do Amazonas, acompanhado de uma segunda parte, dedicada a mostrar os meios que devem usados para a melhor exploração das riquezas do tesouro revelado e inventariado.

O fato de haver vivido por quase duas décadas no vale amazônico dedicando-se a estudá-lo em todos os seus aspectos, permitiu-lhe reconstituir na prisão, com o auxílio de outros missionários presos que também haviam vivido na região, quadros razoavelmente completos relativos aos recursos naturais, à geografia, aos povos indígenas, às atividades econômicas do extrativismo, da agricultura, fruticultura, pecuária, agroindústria, navegação, exploração mineral, madeireira e de aproveitamento de uma vasta quantidade de plantas medicinais. Ao escrever Tesouro descoberto no rio das Amazonas, João Daniel institui o que poderíamos reconhecer como um novo padrão científico de interpretação da Amazônia que dificilmente será atingido por autores até mesmo da atualidade, sobretudo se considerarmos o fato de que na prisão não teve acesso aos dados eventualmente disponíveis em seu tempo. O importante, nesse sentido, é que seu método de apresentação dos objetos examinados é o da experiência empírica, da observação direta, do conhecimento concreto que possuía dos assuntos que tratava. Sua experiência pessoal era complementada pela de outros missionários e informantes que tiveram certamente um papel essencial na confirmação de várias de suas hipóteses.

João Daniel via a Amazônia não apenas como uma das regiões mais ricas do mundo do ponto de vista de seus recursos naturais. Para isso sempre comparava suas particularidades com as singularidades de outras paisagens do mundo, o que revelava ser possuidor de um conhecimento bastante denso sobre os outros povos e países, isso com certeza como um benefício da formação intelectual e científica dos membros de sua ordem religiosa. Os jesuítas conseguiram reunir um vasto conhecimento geográfico, econômico, cartográfico e etnológico de povos e regiões de todo o mundo, o que lhes possibilitava não apenas estabelecer comparações esclarecedoras, mas transferir conhecimentos, tecnologias e modelos de exploração de um continente a outro. Esse domínio de informações em âmbito mundial está presente na visão que nos oferece João Daniel das possibilidades futuras de prosperidade e aproveitamento das riquezas do vale do Amazonas. 


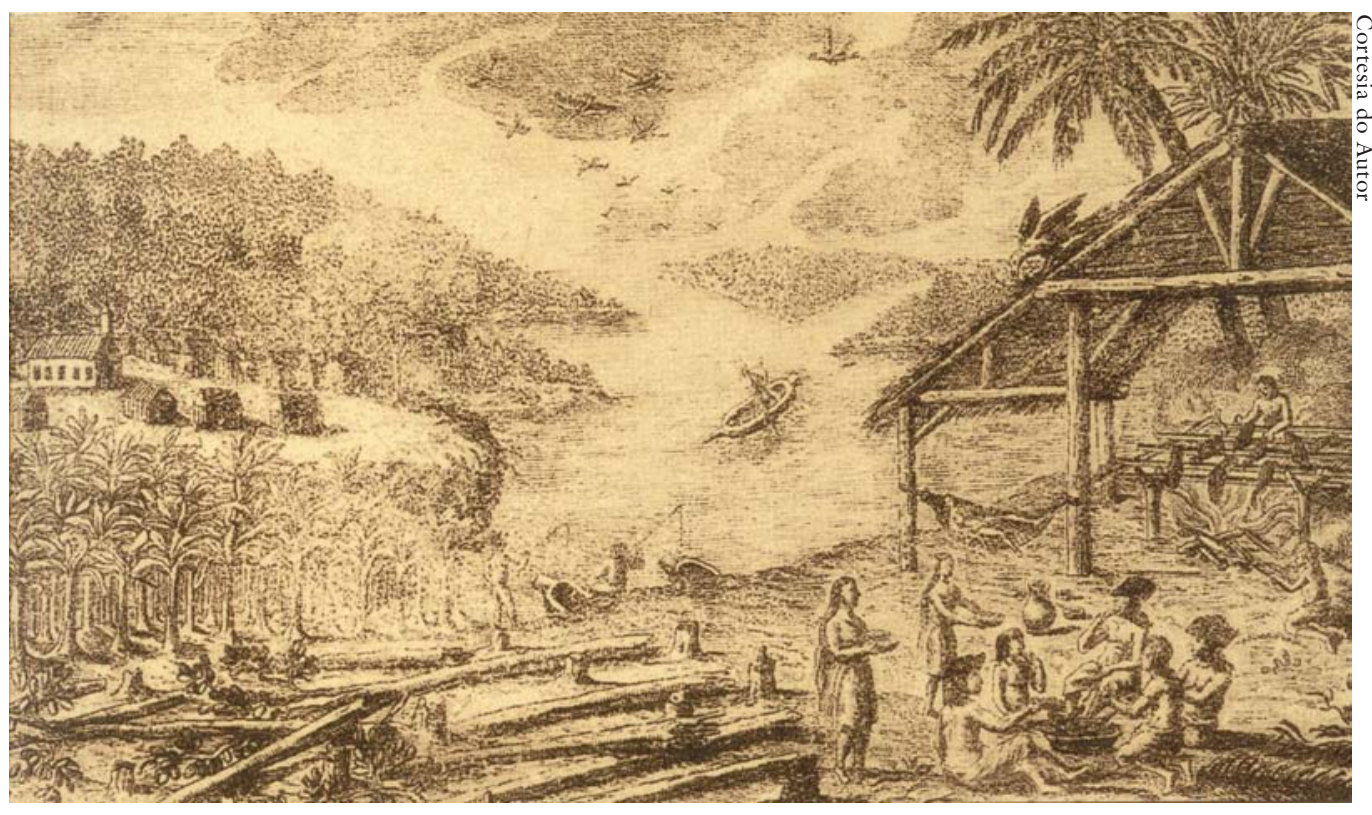

Acreditava na necessidade de transformações substanciais nas técnicas tradicionais indígenas presentes na agricultura. Uma de suas sugestões é a erradicação gradual da agricultura da mandioca, a seu ver um fator de atraso econômico das comunidades nativas, $\mathrm{e}$ sua substituição por culturas como a do milho, trigo e arroz. Sua percepção de prosperidade regional estava vinculada à noção de modernização, em particular nos setores da agricultura, da navegação e do transporte público.

Um outro aspecto da modernização que freqüentemente é abordado em seu plano de valorização regional é o do fim da escravidão indígena e o estabelecimento de unidades de produ-

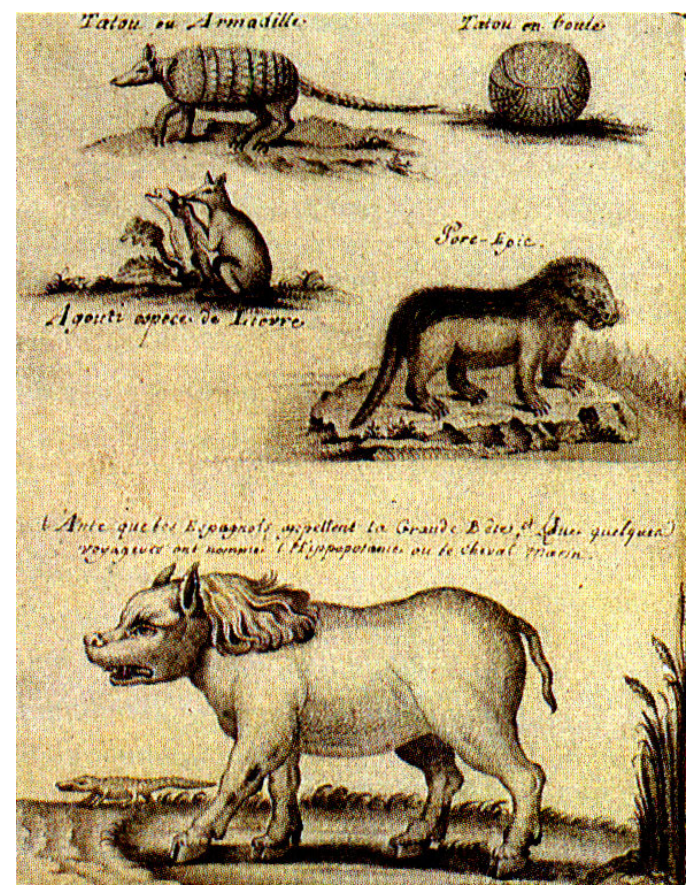
ção econômica mantidas pelo trabalho familiar e das comunidades nativas, associadas às unidades que viessem a se organizar a partir da introdução de imigrantes estrangeiros. A escravidão constituía, para João Daniel, a maior evidência do atraso social e político do vale amazônico. Além das razões morais que condenavam a escravidão, havia a convicção de que a prosperidade dos países e dos povos só ocorria efetivamente com o fim da servidão, com sua substituição pelo trabalho de homens livres. 
Cartas e desenhos do

padre Samuel Fritz.

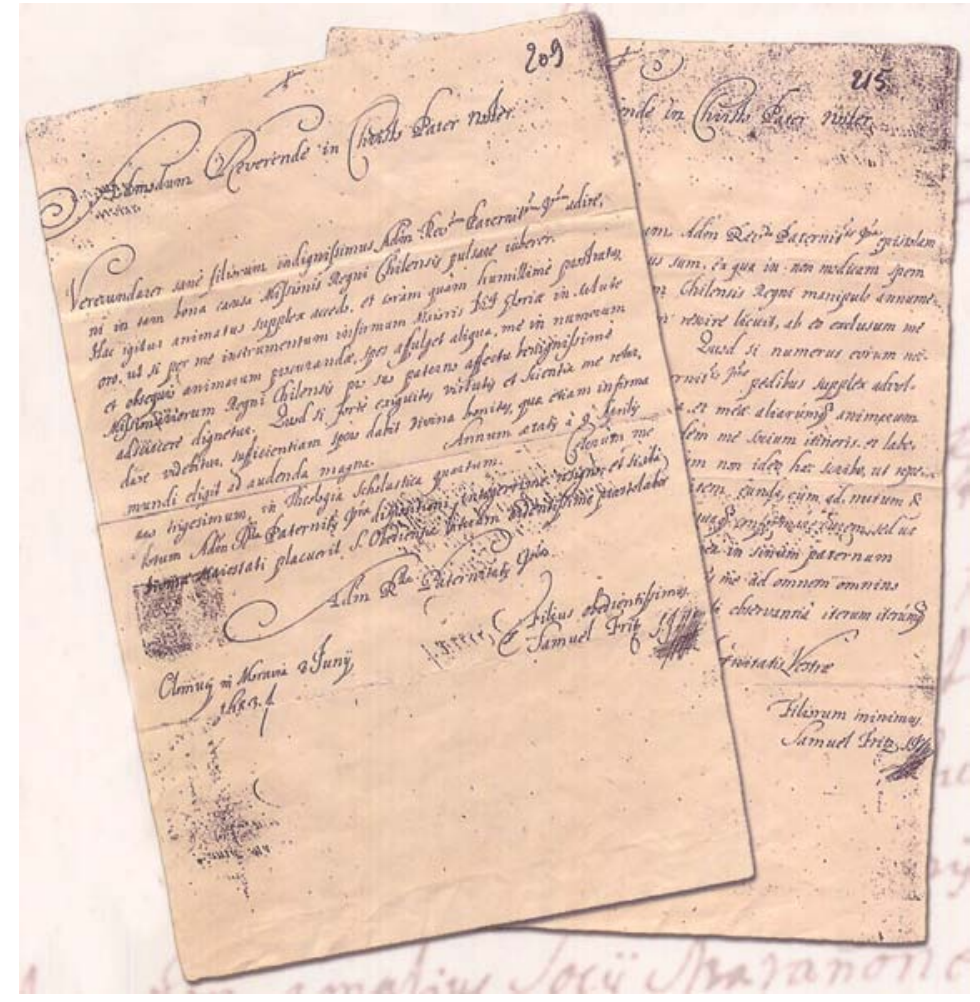

Evidentemente que sua obra encerra pontos de vista às vezes bastante contraditórios em relação à questão da posição do indígena na constituição da sociedade que estava imaginando. Em algumas passagens, por exemplo, sugere que o europeu tem que ser duro com o índio para acostumá-lo a uma vida civilizada e voltada para o trabalho.

Em suas projeções para o surgimento de uma nova sociedade para fazer prosperar o vale amazônico rigorosamente, não haveria lugar para a permanência da maior parte das comunidades nativas conservando seus padrões de organização cultural. Essas deveriam gradativamente incorporar-se aos novos sistemas da organização produtiva voltada para o mercado e para a satisfação das necessidades locais e regionais em termos de consumo e de produção de matérias-primas para a agroindústria em expansão. Se, de uma parte, seu plano de valorização sugeria medidas inovadoras, de outra, na verdade, correspondia à implementação de um processo de ocupação e aproveitamento econômico em pleno curso no vale amazônico, sobretudo por obra dos jesuítas. Esse processo caracterizava-se pela expansão das fazendas de gado, do cultivo sistemático de cacau, da agroindústria da cana-de-açúcar, das olarias, estaleiros navais e, em conseqüência, do incremento de redes cada vez mais extensas de transporte e comércio de produtos do extrativismo, da agricultura e da indústria.

Entre as suas propostas para a incorporação do vale amazônico à civilização estão a de novos partidos arquitetônicos e urbanísticos que poderiam ser expressos através dos seguintes elementos: 1) a arquitetura deve ser concebida 
levando-se em conta, em primeiro lugar, que a região é equatorial e tropical e tem como topografia dominante áreas de extensas planícies cortadas por inúmeros rios. Além disso, a região dispõe de uma grande quantidade e variedade de materiais que devem ser combinados para a construção, com o que é possível adotar um padrão de arquitetura perfeitamente adequado e adaptado ao ambiente e economicamente acessível em razão da ampla disponibilidade dos materiais de construção recomendados pelas características climáticas e físicas da planície amazônica; 2) o traçado das cidades, vilas e demais aglomerações deveria considerar como primeira regra um tamanho limitado para balizar o crescimento urbano e assim evitar o excesso de aglomeração populacional que comprometeria uma distribuição humana equilibrada pelo território. João Daniel sugeria que a criação de cidades deveria seguir, na medida do possível, a distância que existe entre as cidades portuguesas, um modo não apenas de evitar o surgimento indesejável de grandes cidades, mas de assegurar um sistema mais eficiente de ocupação econômica e de uma mais equilibrada distribuição populacional. As cidades deveriam ser construídas preferencialmente em terrenos elevados e arejados como medida de segurança contra as inundações e regime de cheias e vazantes, com o que se garantiria também melhores condições sanitárias, pois essa localização também buscava evitar a proximidade de águas paradas e charcos, fontes de doenças. As cidades e vilas deveriam manter o costume indígena de fixação à margem dos rios, paranás e igarapés, como um meio eficaz de facilitar a navegação, a comunicação e o transporte.

A cidade era percebida como um importante espaço do novo modelo de ocupação e era por meio dela, sobretudo, que se efetuariam as mudanças na organização tradicional das comunidades nativas com a emergência de novos padrões de sociabilidade instituídos pela economia voltada para o comércio regional e externo.

No desenvolvimento de um sistema de navegação e transporte a ser mantido como um serviço público, João Daniel via o principal fator de independência do homem indígena, pois estaria sendo desobrigado do encargo mais penoso e prejudicial em benefício de seu envolvimento com as atividades diretamente produtivas e capazes de lhe oferecer sua gradual independência de sua condição de servo dos europeus. Grande parte do tempo dos índios era gasto em seu trabalho de remeiros que, segundo João Daniel, não apenas os afastava das atividades produtivas como constituía um fator de desagregação da comunidade e da família indígena pelos seus longos e freqüentes afastamentos de suas localidades de vida. Em razão dessa situação, há registro de inúmeros casos de abuso e violência sexual contra as mulheres que se encontravam sozinhas e isoladas em suas localidades, assim como o rapto de mulheres e crianças. A desestruturação familiar aparecia como uma situação extremamente condenável para a prosperidade das comunidades nativas em direção ao seu envolvimento com os padrões de expansão econômica. 


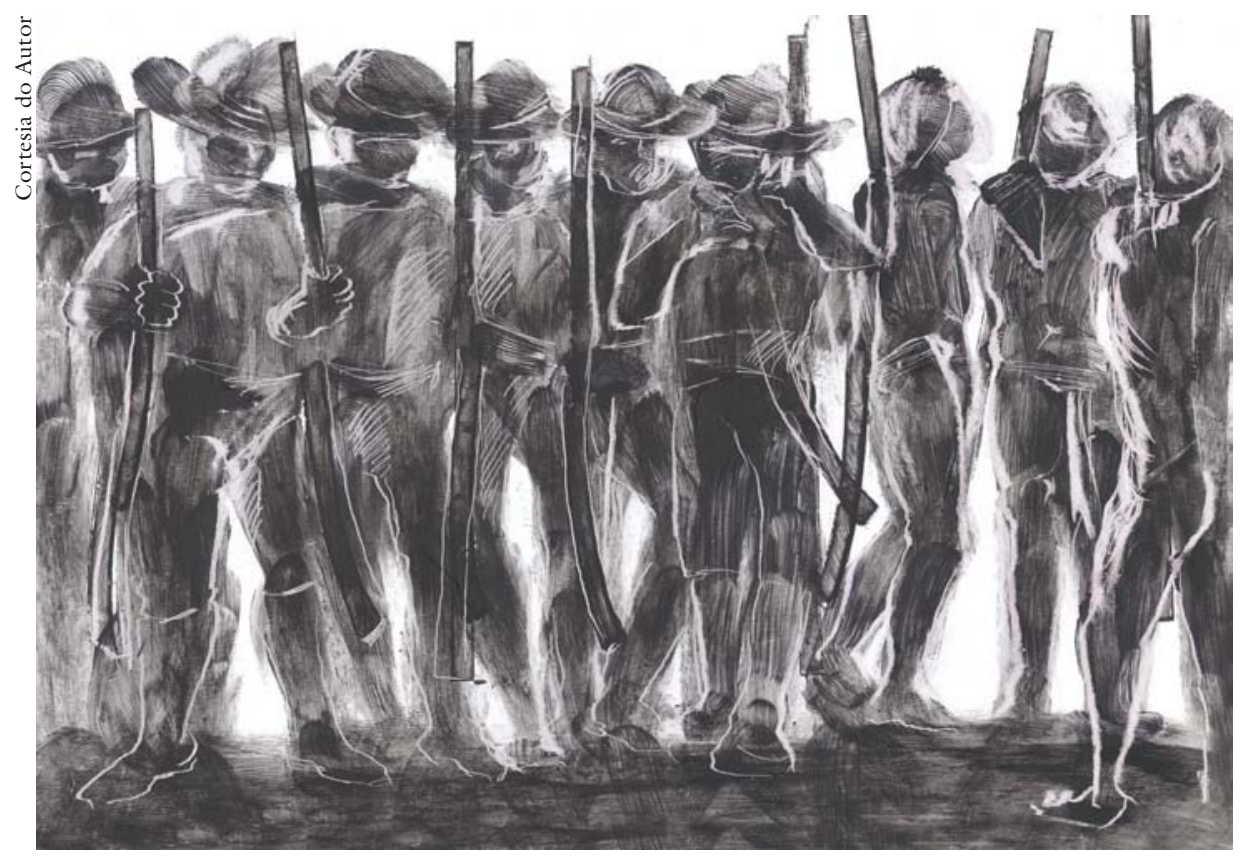

Desenhos de Carlos Rojas.

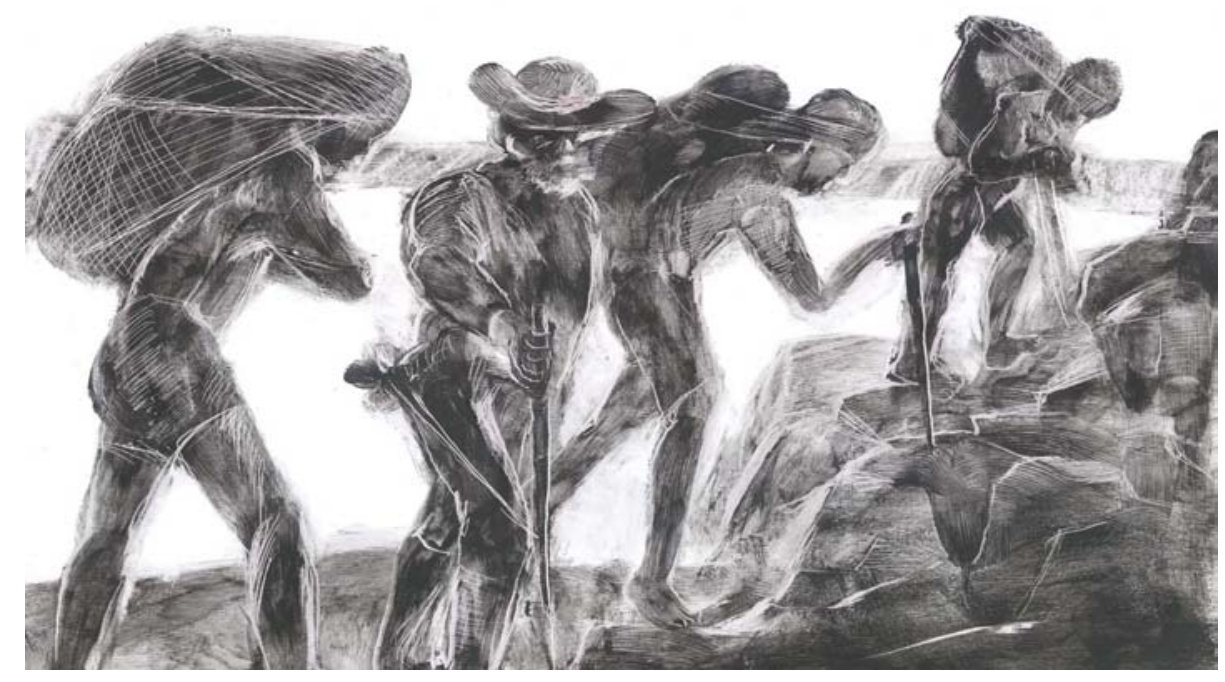

Vários aspectos poderiam ainda ser mencionados em relação ao plano de valorização do vale amazônico que estão contidos em sua obra. Entre esses certamente deverão merecer a atenção do leitor suas sugestões para o aproveitamento dos cursos fluviais em engenhosos sistemas de irrigação, o desenvolvimento de projetos de um tipo de embarcação mais leve utilizando um sistema de velas rotativas, o aproveitamento das diversas madeiras na construção civil, no artesanato, na indústria naval e no comércio de exportação. Recomenda igualmente a identificação das plantas medicinais e seu aproveitamento industrial e comercial como uma das possibilidades de incremento econômico regional. 
Para que todas essas possibilidades se concretizem é necessário, entretanto, que o homem do vale amazônico se torne apto a desenvolvê-las, o que implica um amplo processo de educação como principal meio de mudança cultural. Em diversos momentos de seus escritos, João Daniel formula idéias que, em conjunto, correspondem a uma ampla reforma educacional e cultural da sociedade regional em suas diversas particularidades e especificidades locais.

É possível afirmar que sua proposta de reforma ultrapassa o ideário jesuítico de reforma intelectual e moral dos povos com os quais entrava em contato e com quem passava a atuar não apenas na esfera da catequização, mas, sobretudo, de implementação de atividades de produção econômica organizada a partir de uma nova racionalidade inerente ao universo do mercado.

Um ponto que deve ser ainda mencionado em relação às suas idéias de uma nova maneira de viver na Amazônia é aquele referente à adaptação dos que chegam em termos de alimentação, ritmo de trabalho e, sobretudo, do modo de vestir. As roupas pesadas devem ser deixadas nos locais de origem, pois o clima pede pouca roupa que deve ser confeccionada com tecidos leves.

Ao nos determos em obras como a de João Daniel passamos a perceber não apenas a sua riqueza de informações, mas em especial o quanto também significa o seu desconhecimento.

Por outro lado, pretendíamos também ressaltar o sentido que existe para uma compreensão mais satisfatória dos modos pelos quais a Amazônia e o próprio Brasil têm sido pensados e interpretados tendo como ponto de partida um núcleo perfeitamente identificável de idéias, noções, conceitos e preconceitos que constitui o fundamento dessas obras. É necessário descobrir e compreender como suas idéias surgem, se investem de significação e percorrem os espaços reais e imaginários da vida da sociedade.

De como as idéias viajam, fascinam e moldam nossos espíritos, sonhos, utopias. Esse é um empreendimento apenas iniciado e que deve ser ampliado com o auxílio da combinação de diversas abordagens teóricas e de diferentes instrumentos de investigação de distintos campos de conhecimento, alguns dos quais pouco utilizados até o momento em trabalhos desse tipo.

Bibliografia

ACUÑA, Cristóbal de. Novo descobrimento do grande rio das Amazonas - 1641. Rio de Janeiro, Agir, 1994.

AGUIAR, Ronaldo Conde. Pequena bibliografia critica do pensamento social brasileiro. Brasília/ São Paulo, Paralelo 15/ Marco Zero, 2000.

ARAÚJO, André Vidal. Sociologia de Manaus - aspectos de sua aculturação. Manaus, Fundação Cultural do Amazonas, 1974.

ABOU, Selim. L'identité culturelle. Paris, Anthropos, 1981. 
AVÉ-LALLEMANT, Robert. No Rio Amazonas (1859). Belo Horizonte/ São Paulo, Itatiaia/ Edusp, 1980.

BATISTA, Djalma. Letras da Amazônia. Manaus, Livraria Palácio Real, 1993.

. Amazônia-cultura e sociedade. Manaus, Editora Valer/ Governo do Estado/ Editora da Universidade Federal do Amazonas, 2003.

. Da habitabilidade da Amazônia. Rio de Janeiro, Instituto Nacional de Pesquisa da Amazônia, IBGE, 1965.

. "Brancos e índios na formação da Amazônia". Revista da Academia Amazonense de Letras. Manaus, ano LV, nº 16, dez. 1974.

. O complexo da Amazônia (análise do processo de desenvolvimento). Rio de Janeiro, Conquista, 1976.

BETTENDORFF. João Felipe. Crônica da Missão dos Padres da Companhia de Jesus no Estado do Maranhão. 2 ${ }^{\underline{a}}$ ed., Belém, Fundação Cultural do Pará Tancredo Neves/ Secretaria de Estado da Cultura, 1990.

BUFFON. Del Hombre. México, Fondo de Cultura Económica, 1986.

BRAUDEL, Fernand. História e ciências sociais. Lisboa, Presença, 1986.

CARJAVAL, Gaspar de; ROJAS, Alonso de e ACUÑA, Cristóbal de. Descobrimentos do rio Amazonas. São Paulo, Nacional, 1941.

CASTRO, Eduardo Viveiros de e CUNHA, Manuela Carneiro da. Amazônia-Etnologia e história indígena. São Paulo, Núcleo de História Indígena e do Indigenismo da USP/ Fapesp, 1993.

CORRÊA DA SILVA, Marilene. Opaiz do Amazonas. Manaus, Editora da Universidade do Amazonas, 1996.

COSTA, Cruz. Panorama da história da filosofia no Brasil. São Paulo, Cultrix, 1960.

CRULS, Gestão. Hiléia Amazônica - aspectos da flora, fauna, arqueologia e etnografia indigenas. $4^{\mathrm{a}}$ ed., Rio de Janeiro, José Olympio, 1976.

CARDOSO DE OLIVEIRA, Roberto. Identidade, etnia e estrutura social. São Paulo, Pioneira, 1976.

CASSIRER, Ernst. A filosofia do Iluminismo. Campinas, Editora da Unicamp, 1992.

CUNHA, Euclides da. Um paraíso perdido: ensaios, estudos e pronunciamentos sobre a Amazônia. Rio de Janeiro, José Olympio/ Governo do Estado do Acre, 1986.

DANIEL, João. Tesouro descoberto no rio Amazonas. Rio de Janeiro, Biblioteca Nacional, 1976.

. Tesouro descoberto no máximo rio Amazonas. 2 vols., Rio de Janeiro, Contraponto/ Prefeito Municipal de Belém, 2004, 600 p.

DURAND, Gilbert. O imaginário: ensaio acerca das ciências e da filosofia da imagem. Rio de Janeiro, Difel, 1998.

. As estruturas antropológicas do imaginário. São Paulo, Martins Fontes, 2001.

ELIAS, Norberto. O processo civilizador - uma história dos costumes. Rio de Janeiro, Jorge Zahar, 1990. 
EVANS-PRITCHARD, E. E. História do pensamento antropológico. Lisboa, Edições $70,1981$.

FERNANDES, Florestan. A organização social dos Tupinambá. São Paulo, Difel, 1963.

FERREIRA, Alexandre Rodrigues. Viagem filosófica-Memórias. 2 vols., Rio de Janeiro, Conselho Federal de Cultura, 1972. Viagem Filosófica ao Negro. Belém, Museu Goeldi, s/d.

FORTES, Luiz Roberto Salinas. Rousseau: O bom Selvagem. São Paulo, FTD, 1989.

FRANCO, Afonso Arinos de Melo. O indio brasileiro e a Revolução Francesa: as origens da teoria da bondade natural. 2a ed., Rio de Janeiro/ Brasília, J. Olympio/ INL, 1976.

FRITZ, Samuel. Journal of the Travels. Wiesbaden, Hakluyt Society, 1967.

. Diário. Em Pablo Maroni (org.). Noticias autenticas del famoso Rio Marañon. (Monumenta Amazônica). Iquitos, Peru, Centro de Estúdios Teológico de la Amazônia (Ceta), 1988.

- Diário de viagem. Revista do Instituto Histórico e Geográfico Brasileiro. Rio de Janeiro, Imprensa Nacional, t. 81, 1912.

FREITAS PINTO, Renan. "O tesouro de João Daniel”. A Crítica, Manaus, 26 abr. 1996.

. "O hiato antropológico". A Crítica. Manaus, 2 maio 1996.

. "Reconstruir o pensamento social”. A Crítica. Manaus, 1ํo jun. 1996.

. "Em busca da sociodiversidade". A Crítica. Manaus, 6 jun. 1996.

“"A geografia do exótico”. A Crítica. Manaus, 20 jun. 1996.

. "Notas de um 'voyeur' alemão na Amazônia (sobre Ave-Lallement)". A Crítica. Manaus, 27 jun. 1996.

. "Alexandre Rodrigues Ferreira - A tartaruga sob o olhar do século XVIII". A Critica. Manaus, 8 ago. 1996.

. "Os canibais de Montaigne”. A Crítica. Manaus, 15 ago. 1996.

1996.

"Florestas culturais propõem novos paradigmas". A Crítica. Manaus, 22 ago.

. “A antropologia do rio Negro”. A Crítica. Manaus, 29 ago. 1996.

. "O lugar das etnociências". A Crítica. Manaus, 22 out. 1996.

. “Samuel Fritz, delírio e esclarecimento”. A Crítica. Manaus, 2 jan. 1997.

. "Os climas e a diversidade humana (sobre Buffon)". A Crítica. Manaus, 10 jan.

1997.

1997.

“Arthur Reis: identificação e revelação das fontes”. A Crítica. Manaus, 16 jan.

. "La Condamine, a aventura da ciência”. A Crítica. Manaus, 23 jan. 1997.

. “Dos heróis sem história”. A Crítica. Manaus, 6 fev. 1997.

. “Em busca da história - João Daniel”. A Crítica. Manaus, 27 fev. 1997. 
abr. 1997.

. "Alexandre Rodrigues Ferreira - O naturalista retorna". A Critica. Manaus, 10 . “As fontes da viagem filosófica”. A Crítica. Manaus, 3 abr. 1997.

GASCAR, P. Buffon. Paris, Gallimard, 1983.

LÉCRIVAIN, P. Pour une plus grande gloire de Dieu. Les Missions Jésuites. Paris, Gallimard, 1991.

LA CONDAMINE, Charles Marie de. Viagem pelo Amazonas 1735-1745. Rio de Janeiro/São Paulo, Nova Fronteira/ Edusp, 1992.

GERBI, Antonello. O Novo Mundo: história de uma polêmica: 1700-1900. São Paulo, Companhia das Letras, 1996.

GHEERBRANT, Alain. L'Amazone un géant blessé. Paris, Gallimard, 1988.

HANKE, Lewis. El prejuicio racial em el Nuevo Mundo: Aristóteles y los indios de Hispanoamérica. Santiago do Chile, Editorial Universitária, 1958.

. Aristóteles e os indios americanos. São Paulo, Livraria Martins Editora, s/d.

HEGEL, G. W. F. Fenomenologia del Espiritu. México, Fondo de Cultura Económica, 1985.

. Lecciones sobre la Filosofia de la História universal. Madrid, Alianza, 1986.

. Filosofia da História: Brasília, Editora Universidade de Brasília, 1995.

MAXWELL, Kenneth. Marquês de Pombal, paradoxo do Iluminismo. Rio de Janeiro, Paz e Terra, 1996.

MONTAIGNE, Michel de. Ensaios. São Paulo, Abril Cultural, 1972. (Coleção Os Pensadores, vol. XI).

MONTESQUIEU. Do espirito das leis. São Paulo, Abril Cultural, 1973. (Coleção Os Pensadores, vol. XXI).

MUMFORD, Lewis. A cultura das cidades. Belo Horizonte, Itatiaia, 1961.

OLIVEIRA, José Aldemir de. Cidade na selva: urbanização das amazonas. Tese de doutorado, São Paulo, Universidade de São Paulo, 1995.

RICOEUR, Paul. Interpretação e ideologias. Rio de Janeiro, Francisco Alves, 1977.

. O conflito das interpretações: ensaios de hermenêutica. Rio de Janeiro, Imago, 1978.

ROUSSEAU, J. J. Do contrato social e discurso sobre a origem e os fundamento da desigualdade entre os homens. São Paulo, Abril Cultural, 1972. (Coleção Os Pensadores, vol. XXIV).

REIS, Arthur Cezar Ferreira. Manáos e outras vilas. Manaus, 1934. 1942.

. A conquista espiritual da Amazônia. São Paulo, Escolas Profissionais Salesianas,

SPIX E MARTIUS. Viagem pelo Brasil 1817-1820. Belo Horizonte/ São Paulo, Itatiaia/ Edusp, 1981 (3 vols.).

SAHLINS, Marshall. Cultura e razão prática. Rio de Janeiro, Zahar, 1979.

SOUZA, Octávio. Fantasia de Brasil: as identificações na busca da identidade nacional. São Paulo, Escuta, 1994. 
SOUZA, Márcio. A expressão amazonense. Do colonialismo ao neocolonialismo. São Paulo, Alpha Omega, 1978.

STAROBINSKI, Jean. Montaigne em movimento. São Paulo, Companhia das Letras, 1992.

TAVARES BASTOS, A. C. O vale do Amazonas. São Paulo/ Brasília, Nacional/ INL, 1975.

TOCANTINS, Leandro. O Rio comanda a vida. Rio de Janeiro, A Noite, 1952.

. Euclides da Cunha e o paraíso. Rio de Janeiro/ Brasília, Civilização Brasileira/ INL, 1978.

THOMAS, Keith. O homem e o mundo natural: mudanças de atitudes em relação às plantas e aos animais (1500-1800). São Paulo, Companhia da Letras, 1988.

WEBER, Max. Ensayos sobve Sociologia de la Religión (3 vols.). Madrid, Taurus, 1983. . História Econômica General. México, Fondo de Cultura Económica, 1987.

VENTURA, Roberto. Estilo tropical - história cultural e polêmicas literárias no Brasil. São Paulo, Companhia das Letras, 1991.

VOVELLE, Michel. Ideologias e mentalidades. São Paulo, Brasiliense, 1987.

RESUMO - ESTE TEXTO indica os traços principais da constituição do pensamento social sobre a Amazônia e como um conjunto relativamente restrito de idéias tem sido acionado para construir as representações passadas e presentes desse universo cultural.

ABSTRACT - THIS TEXT depicts the main features of the constitution of social thinking on the Amazon and how a relatively limited set of ideas has been called forth to establish past and present representations of this cultural universe.

Palavras-chave: Amazônia, Sociedade, História Cultural, História das Idéias.

Keywords: Amazon, Society, Cultural History, History of Ideas.

Renan Freitas Pinto é professor titular do Departamento de Ciências Sociais da Universidade Federal do Amazonas (Ufam).

Texto recebido em 4 de fevereiro de 2005 e aceito para publicação em 26 de fevereiro de 2005 . 